\title{
Evaluation of Sealing Potential near Gas Chimneys-the Gippsland Basin, Australia
}

Hadi Nourollah, Milovan Urosevic

\section{Abstract}

Gas chimneys are geological features that are associated with seal bypass systems. Knowledge of the capacity of the seal is important for the evaluation of the petroleum systems and Carbon Capture and Storage (CCS) studies. The seal is breached when the capillary pressure threshold is exceeded by the underlying buoyancy pressure. The chaotic seismic character that is generally associated with the gas chimneys has been studied previously to evaluate the origin and geometry of the chimneys. Seismic attributes have also been used to determine the character of the gas chimneys and the potential association of hydrocarbon fields. However, it is important to evaluate the sealing potential of the cap rock in the vicinity of the gas chimney. This paper demonstrates that the chimney can be used as a calibration point and, with the use of seismic attributes, variations of sealing capacity can be evaluated. Out of many existing seismic attributes, understanding the shale structure is crucial to narrow the search criteria for the right class of attributes. Using the most useful stream of seismic attributes, the average sealing potential of the Lakes Entrance Formation is estimated. The sealing capacity map across the field is then shown to help evaluate the prospectivity of the area of study and may upgrade subsequent play fairway maps.

Keywords: Sealing Capacity, Chimney, Seismic Anisotropy, Seismic Attributes, CCS 


\section{Introduction}

Chimneys are expressed as vertical chaotic disturbances on seismic sections related to the propagation of fluids (especially gas) through fissures and fractures in rocks. They can be indicative of mud diapirism, active gas seepage, migration pathways or hydrocarbon reservoirs (Aminzadeh et al., 2002). Seal bypass systems (Cartwright et al., 2007) can also be manifested as gas chimneys. The sealing potential of a geological unit is generally expressed in terms of Geometry, Integrity and Capacity (Kaldi and Atkinson, 1997). Geometry and Integrity of the seal refer to its spatial extent and presence/lack of breaching faults respectively. The seal is breached when the buoyancy pressure of the fluid column exceeds its sealing capacity. The sealing capacity is generally a measure of the capillary pressure needed for the non-wetting phase to invade the (smallest) pores. Once this invasion happens, the connection of gas is established through the seal and the seal leaks (Sneider et al., 1997; Vavra et al., 1992). Leakage is sometimes accompanied by fracturing as result of gas pressure and movement. A combination of these fractured rocks with some degree of fluid saturation accounts for the seismic signature of what is referred to as a chimney. Seismic data has been effectively used to describe the Geometry and Integrity of seals, however the association of sealing capacity with seismic data is not straightforward.

A classic gas chimney in the Gippsland Basin was studied by Nourollah et al. (2010). Validation of the gas chimney interpretation of the seismic anomaly has been provided by hydrocarbon sniffing in the water layer (Goldie Divko et al., 2010b). Seismic attributes were shown to be of significance in delineating the extent of the gas chimney. However, the study stopped short of elaborating on the seal capacity of the area. In this paper, building on the previous work, we will present the methodology and results of the seal capacity evaluation in the vicinity of the gas chimney. 


\section{Geology}

The Gippsland Basin is an east-west trending feature (Figure 1) that formed as a consequence of the break-up of Gondwana in the Mesozoic (Norvick et al., 2001); Rahmanian et al. (1990). The basin's evolution is recorded by three major depositional sequences ranging from Early Cretaceous to recent in age, and the overall tectonic control on the sedimentary systems of the basin is manifested by a series of angular unconformities.

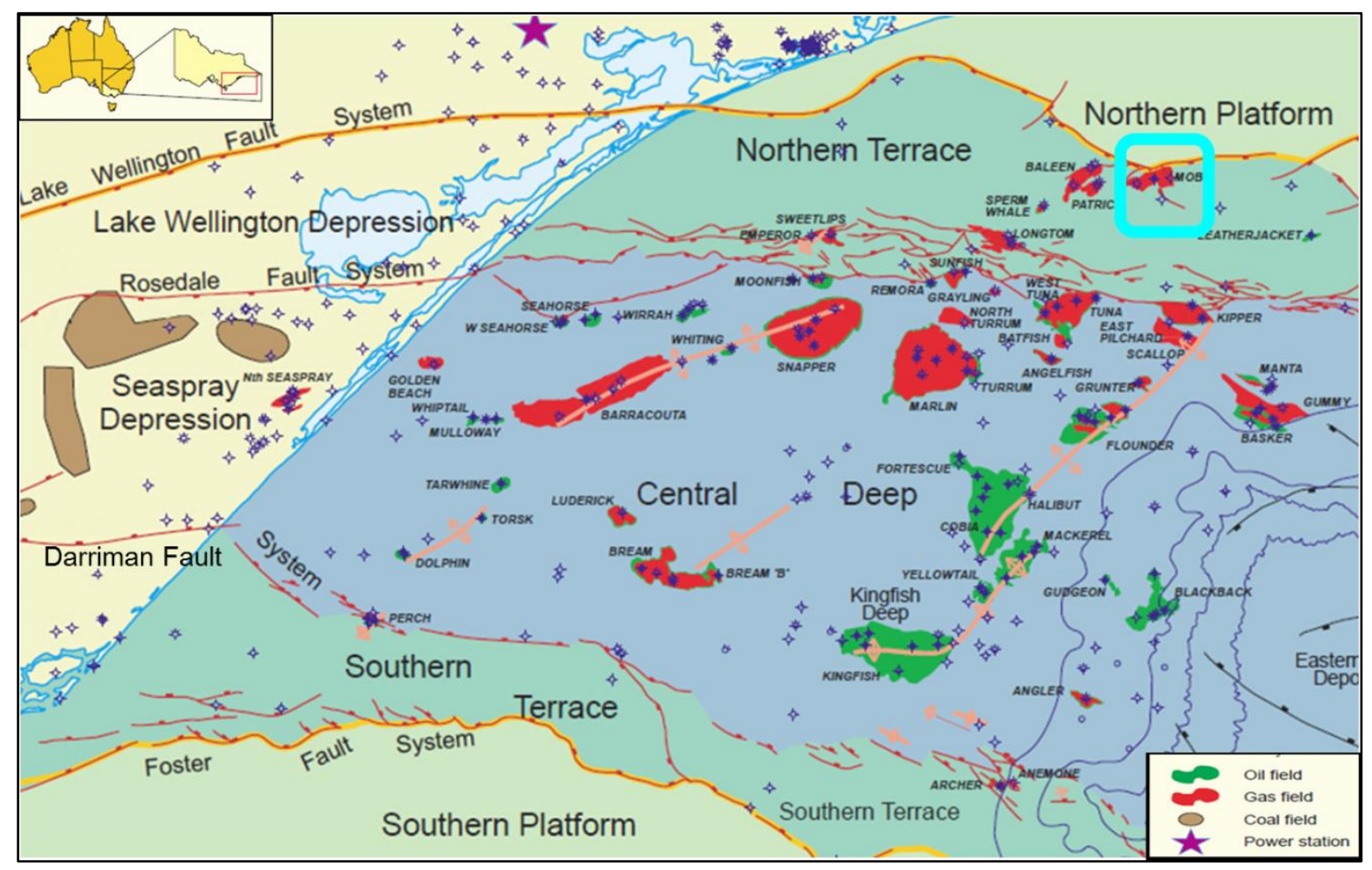

Figure 1. Structural elements of the Gippsland Basin and a general distribution of hydrocarbon fields (after Goldie Divko et al. (2010b)). The area of study (AOI) is marked with the blue rectangle.

During the first rifting period, extension was directed approximately north-south. The Cretaceous rift is related to the break-up of Australia from Antarctica (Duddy and Green, 1992). The rift system extended along the southern margin with NW to SE trending growth-faults bounding the halfgrabens. The generated accommodation space controlled the deposition of the Strzelecki Group (Figure 
2). The Strzelecki Group is mostly non-reservoir volcaniclastic fluvial sediments but contains quartzose potential reservoirs in places (Holdgate \& Mcnichol, 1992). The sandstones are fluvial, deposited by meandering to braided rivers subject to major floods, and the claystones were deposited on floodplains where soils developed under widespread forests.

A second phase of rifting occurred from the Late Cretaceous to Eocene, associated principally with Tasman Sea spreading, and this produced a classic extensional basin geometry comprising a depocentre (the Central Deep) flanked by platforms and terraces to the north and south. The Darriman and Foster fault systems on the southern basin margin, and the Rosedale and Lake Wellington fault systems on the northern margin, define these areas. The second phase of rifting provided the accommodation space within which the Latrobe Group was deposited. The Latrobe Group is mostly fluvial to coastal sediments, consisting of quartzose reservoir sandstones interbedded with coals and carbonaceous claystones, but also includes shallow-marine glauconitic sediments deposited seawards of the coast forming a transgressive veneer over the non-marine parts of the Latrobe Group. This rifting phase was punctuated by a series of minor uplift events that led to the development of local unconformities (those recognized between the four subgroups of the Latrobe Group - the Emperor, Golden Beach, Halibut and Cobia subgroups), followed by a period of drift.

The regional sealing facies of the Oligocene Seaspray Group was deposited during the post-rift sag phase following the conclusion of Tasman Sea rifting in the Eocene and the onset of rapid seafloor spreading between Australia and Antarctica. The Lakes Entrance Formation, deposited as a result of marine transgression during this period, is widely recognized as the sealing unit in the offshore Gippsland basin (Partridge et al. (2012), Goldie Divko et al. (2010a), Rahmanian et al. (1990)). However, the Lakes Entrance Formation itself is a representative term for the top seal and its stratigraphy is more complex. Partridge et al. (2012) introduced the the Bassian Rise units within the Seaspray Group and 
concludes that the Lakes Entrance Formation is coincident with the fifth (and oldest) Bassian Rise Unit (BR5 in Figure 2). The Lakes Entrance Formation marks the onset of lithological change from calcareous Gippsland Limestone to marl and marine shales.

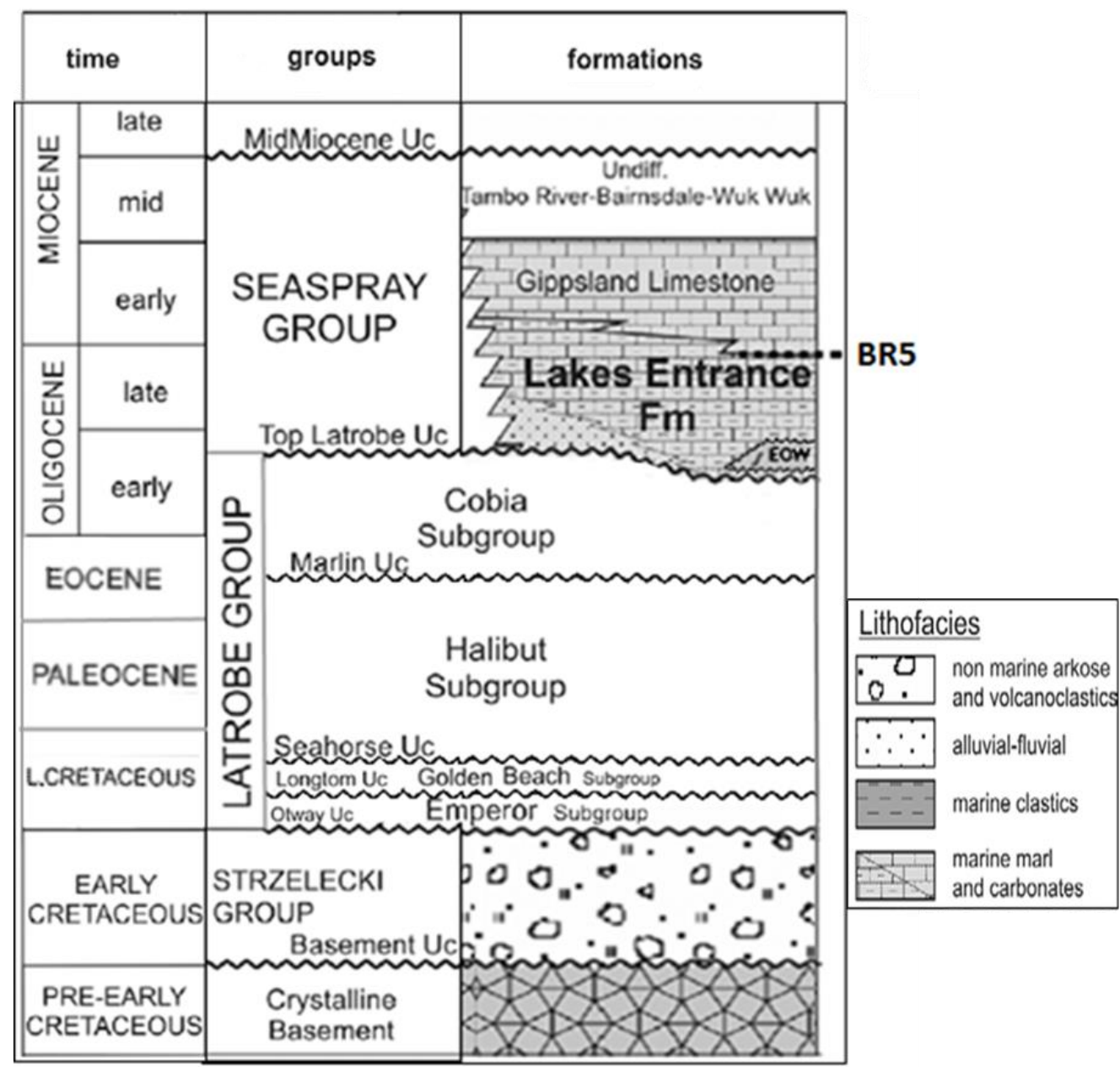

Figure 2. Simplified stratigraphic chart of the Gippsland Basin (after Ciftci et al. (2014)). Younger sediments of PlioPleistocene are undifferentiated in the area of study. 


\section{Area of Study}

The northern margin of the offshore Gippsland Basin is host to several oil and gas discoveries. In contrast to the southern platform, the northern margin is composed of a number of smaller terraces which run sub-parallel to the Lake Wellington Fault system. The primary target for exploration is the top Latrobe Group sands (or the Gurnard Formation) with examples of success in older sands of Chimaera Formation in nearby Longtom field (Figure 1).

The area of study (Figure 3) is covered by 3D seismic (Moby 3D/ Gap04A) with older 2D lines partly transecting the area. Four wells have been drilled in the AOI: Flathead-1 (1969), Whale-1 (1981), Moby-1 (2004) and Maclean-1 (2005). All four wells intersected the seal and reservoir, but only the first three have vertical (checkshot/VSP) and sonic velocity data. Moby 3D full stack and partial offset stack volumes were available for this study. Although the gas chimney is obvious on the seismic (Figure 4), no public domain report or interpretation of the top seal potential is available for the area. Structural interpretations of the (near) top seal and the top primary reservoir (Latrobe Group) seismic horizons were conducted to define the geometry of the sealing package. Despite the lack of Mercury Injection Capillary Pressure (MICP) samples from the wells, the gas chimney acts as a valid calibration point for the seal failure. 


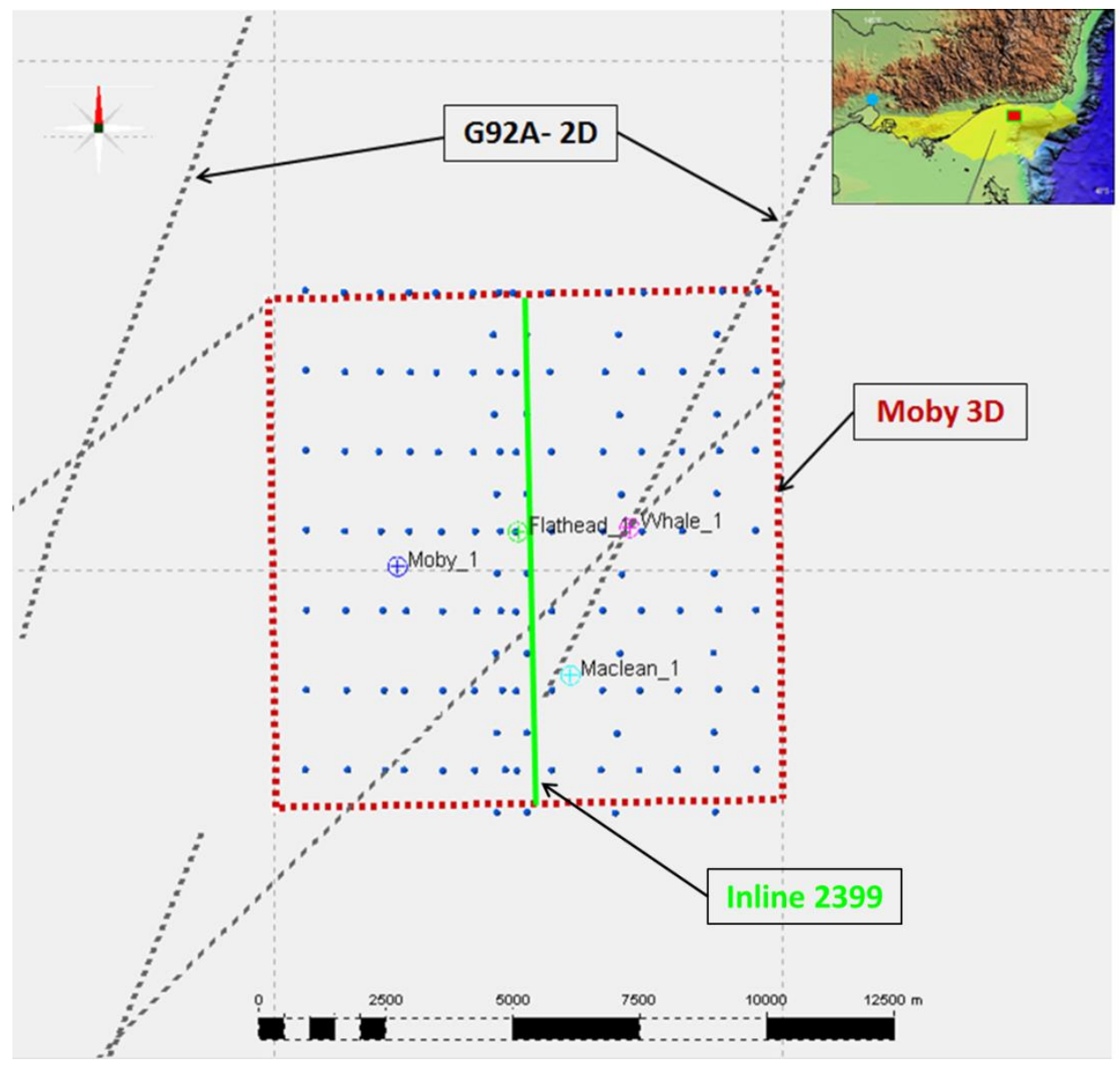

Figure 3. Location map of the Moby 3D survey in the Gippsland basin and the four wells within the area of study. The blue circles within the Moby 3D area are the analysis points for ETA.

\section{The Chimney}

The main gas chimney is located north and north east of Flathead-1. There are other smaller leakage signatures that are visible in the vicinity of the main chimney which are either associated with it or are independent features. The gas leakage appears to have stemmed from the Strzelecki group and breached the seal (aqua to blue interval in Figure 4.). Where the chimney is in full form, it has reached the seabed and its signature can be detected on amplitude-related attributes. The movement of the chimney through the overlying sediments has caused ruptures and fractures that have only encouraged 
the upward movement of the gas. Sub-vertical fracture-sets may well be associated with the chimney, however, a number of such feature are likely due to poor seismic imaging quality around chimney areas.

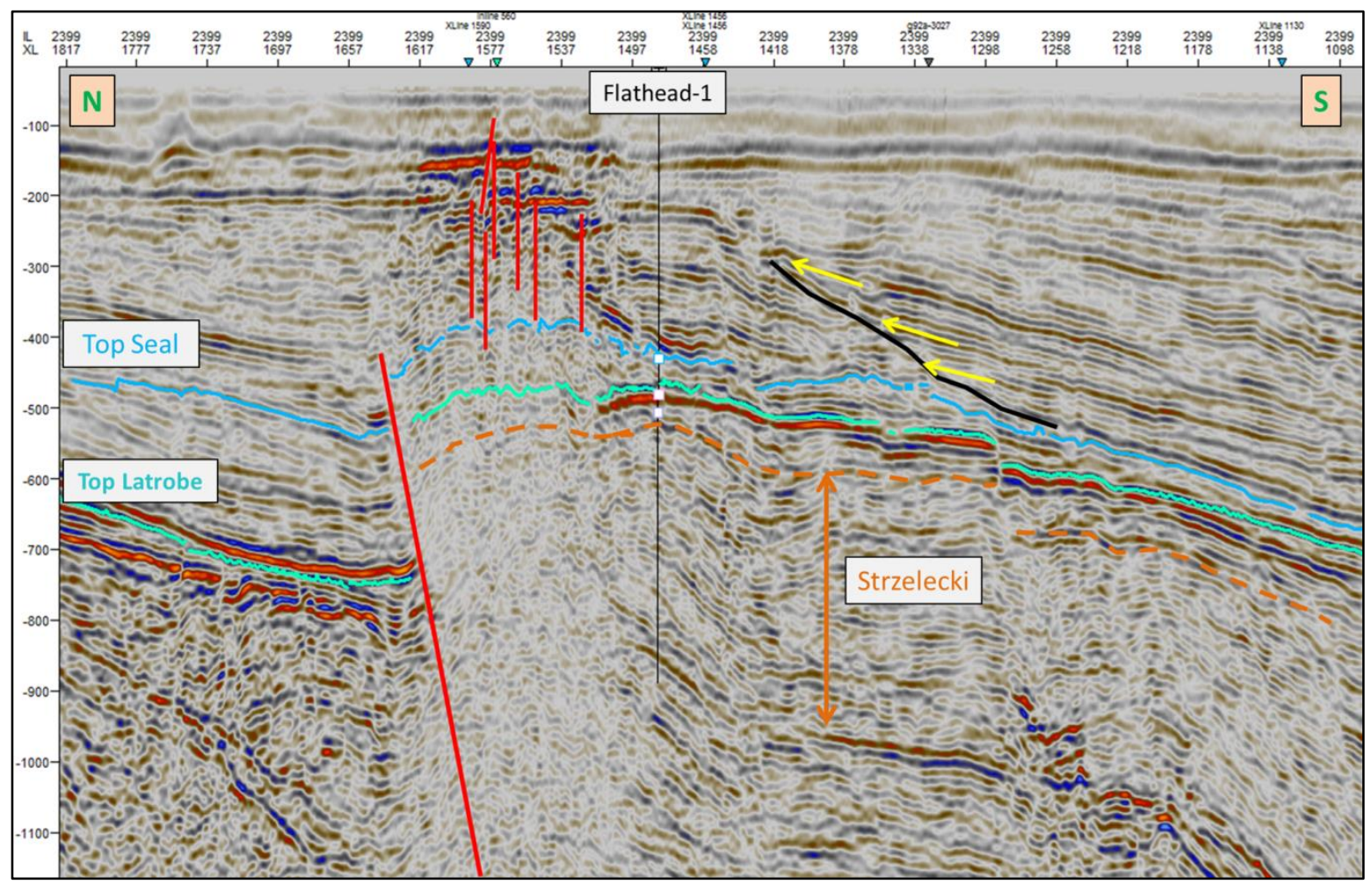

Figure 4. Seismic Inline 2399 east of Flathead-1 shows the main gas chimney in the area of study (in the vicinity of the vertical red lines). The well is projected some 200 meters. Gas infusion through the seal package and the associated brightened reflectors in the shallow is visible.

A reflection intensity attribute is probably the best to map the variation of amplitudes due to presence of gas in the shallow sediments. The response of this attribute on the sea bed horizon shows the lateral extent of the main chimney (Figure 5). Not all of the obviously high amplitude values at the seabed are associated with gas chimneys underneath them. However, the more circular and bunched features, such as the ones to the NE of the main chimney, are somehow related to a leakage feature. Such features can be indicative of either a fault or a weak top seal. Various onlapping packages indicate post deposition erosions which have reduced the effective thickness of the top seal in places. In some areas, especially to the NE of the main chimney (arrows in Figure 5), the cluster of high amplitude 
features suggest faulting have assisted in weakening the top seal integrity or in providing more efficient escape route for the gas underneath.

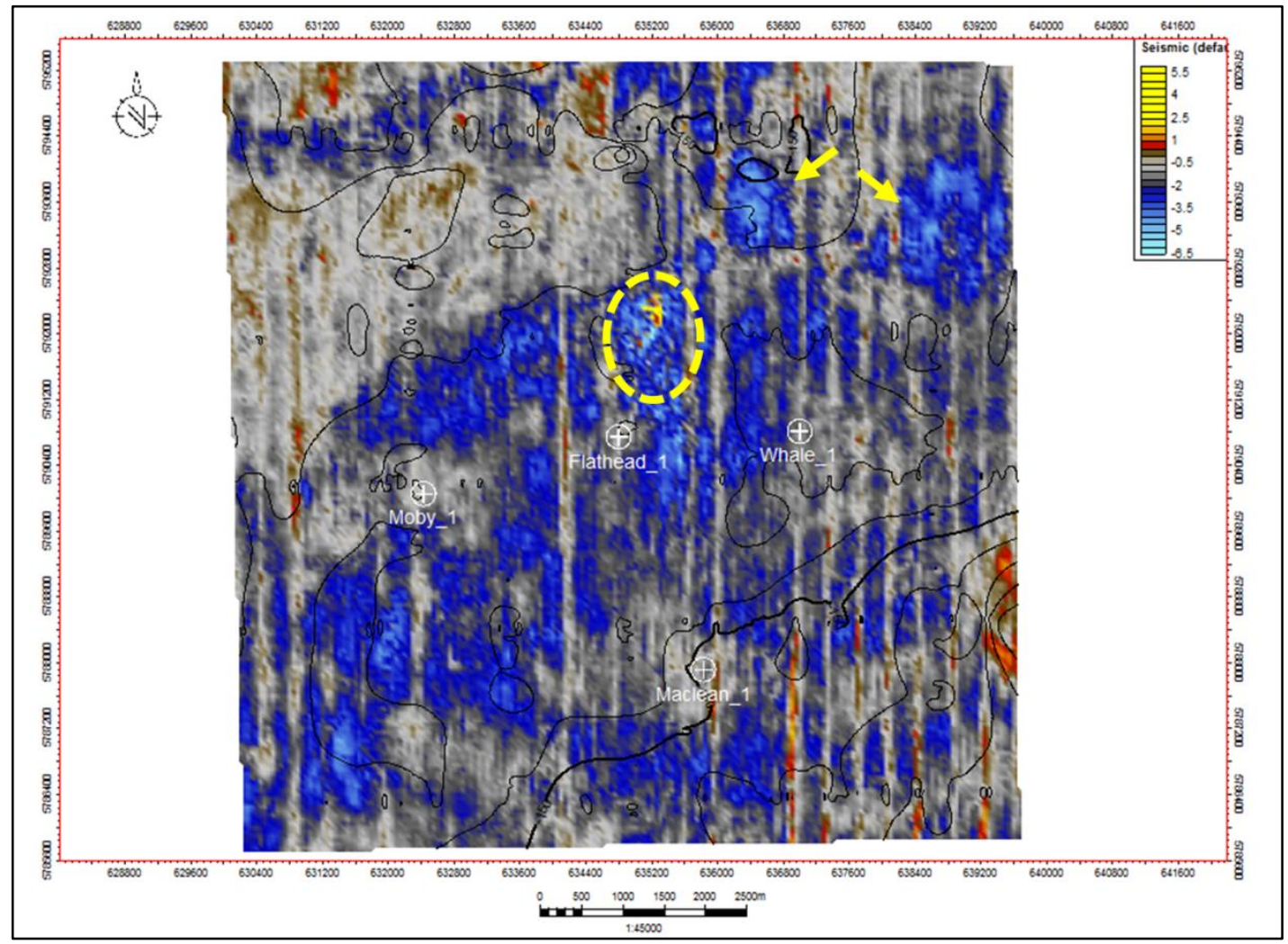

Figure 5. Reflection intensity of the sea bed. The coherent signature of high values of this attribute at the center of the map is associated with the gas chimney (after (Nourollah et al., 2010)). The arrows indicate circular high amplitude areas which are potentially associated with leakage. Acquisition footprints are obvious as N-S trending striations.

Interestingly, the thinnest seal is not directly related to the obvious chimneys. This is in concert with the fact that the top seal capacity is not necessarily related to the thickness of the seal. However the thickness of the Lakes Entrance Formation is relatively thin and gets even thinner at the crest of the Moby high (Figure 6). The Lakes Entrance Formation thickens to the north of the inverted normal fault (Figure 4). Over the crest and south of the structure, the seal thickness varies within a range, but without significant variation. Depth to top Lakes Entrance is as shallow as $\sim 400 \mathrm{~m}$ (near Flathead-1) and increases to in the south to more than $\sim 800 \mathrm{~m}$. 


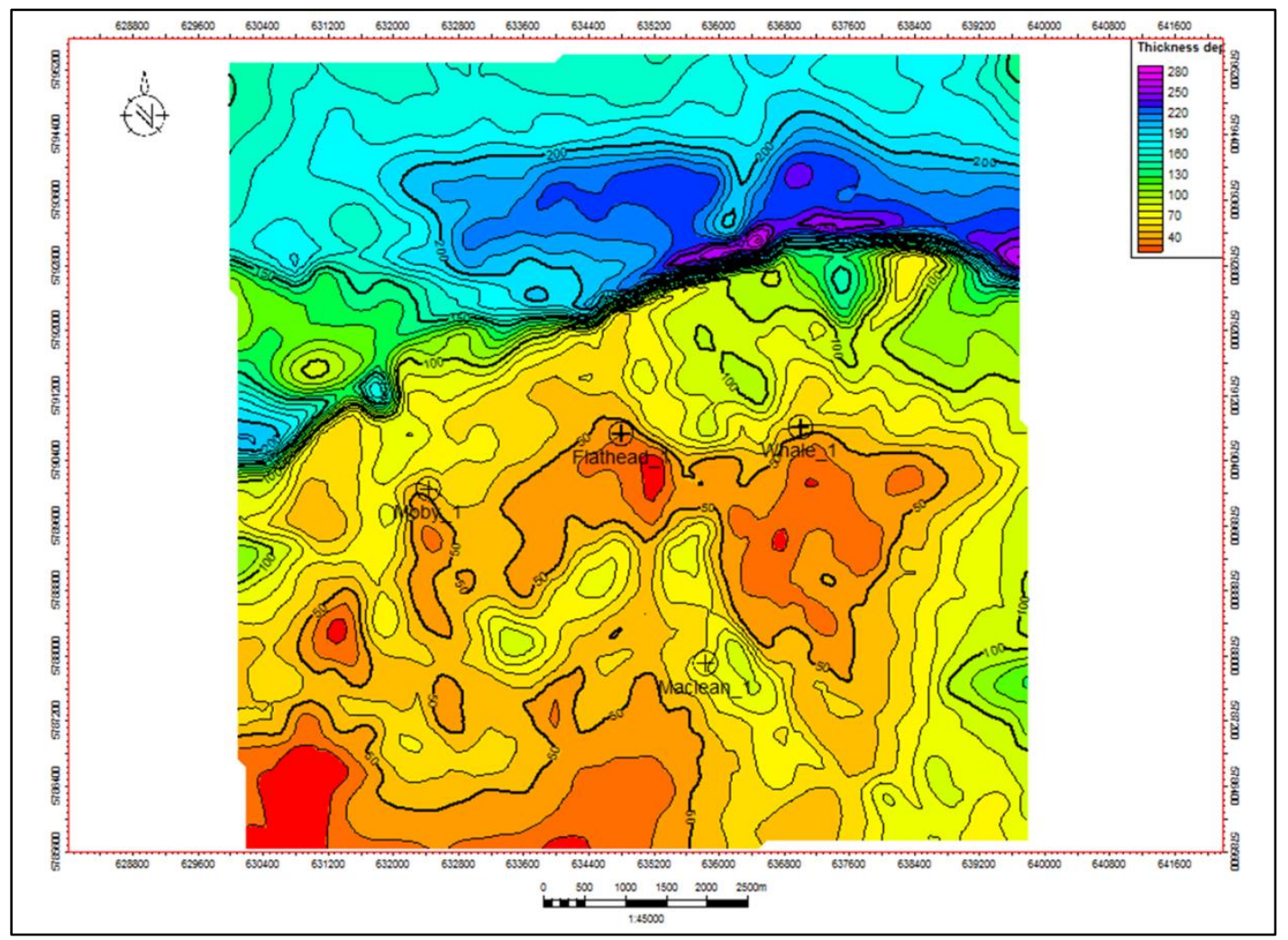

Figure 6. Depth thickness map of the top seal shows a relatively thinner sequence on the paleo-high.

\section{Methodology}

Shales are highly porous rocks but with very limited permeability. It means that their porous space is not connected (or connected with very narrow pipes) and the water layer/molecules in between the clay sheets are tied to the adjacent shale domain and have limited mobility. When an impinging seismic wave passes through rocks, attenuation occurs due to cross-flow of the fluid in the pore space or between layers (Dvorkin and Mavko, 2006). The non-effective pore spaces in shale are abundant enough to absorb a lot of the seismic energy and convert it to heat through their limited viscous flow. This is the reason the Quality Factor (Q) values of shales are among the lowest compared to those of other rocks (Sheriff and Geldart, 1995). The decay in a lossy medium is frequency dependent in a way that higher frequencies get absorbed more quickly. Viscous cross-flow happens when the 
deformation by the passing wave occurs. At lower frequencies, the fluid has time to move and settle, while higher frequencies won't be sensed by the fluid as it requires too rapid move and relaxation period (Dvorkin and Mavko, 2006).

The character of the sealing shale and its response to seismic energy offer four potential avenues for predicting seal quality:

- Impermeable shale should act as near ideal absorbent of seismic energy. With the introduction of capillary pipes, shale may show a reduction of the contrast in its attenuation of seismic energy propagating parallel to the bedding when compared with that propagating perpendicular to the bedding. With increased capillary porosity, better connectivity exists between the capillary pipes and the pore throats are larger. Therefore the cross-flow may be different from that of a shale with tighter pore throats.

- Another aspect is related to the frequency content of the impinging wave with relation to the pore throat size. Smaller radii of capillary pipes (higher capillary pressure, $\mathrm{P}_{c}$ ) will have more difficulty letting the fluid flow at higher frequencies. Therefore, at a constant frequency, smaller pore throats should cause higher attenuation perpendicular to the bedding. There is also the heterogeneity of shales. Narrow band seismic frequencies can be obtained for analysis using the Spectral Decomposition of seismic data.

- Attenuation of seismic waves is higher at larger elastic heterogeneity (Bandyopadhyay et al., 2009). Heterogeneous distribution of pore fluid contents in patches is sensed by the passing seismic waves. Patchy saturation in the pore space has a notable impact on the seismic response (Batzle et al., 2006). It is a likely factor in affecting the seismic quality factor of shales (Delle Piane et al., 2014). A gas chimney is a good example of patchy fluid saturation within the overlying cap rock. The Instantaneous $Q$ is a seismic 
attribute which is a proxy for the rock quality that is measured by seismic data. It has a close relationship with seismic attenuation or inverse Q (Taner, 2001).

- Better laminated shale sequences were shown to have higher sealing capacity (Dawson et al., 2008; Dawson et al., 2004). Better laminated shales may be recognized with seismic data. Nourollah et al. (2015) showed that a particular parameter of the seismic anisotropy, $\varepsilon$ (Thomsen, 1986) can be used to predict the variations of the sealing potential of shale sequences. However, the difference in lithology of seals plays an important role in the separation of their sealing-anisotropy trend one. Such comparison is made for the two seals, one in the Exmouth Sub-basin and one in the Gippsland Basin (Figure 7). smectite is the weakest of clay minerals (and one of weakest of all minerals) in terms of its geomechanical strength (Dewhurst and Hennig, 2003). Common clay minerals that are constituents of shales are Illite, kaolinite, smectite and chlorite. The higher the smectite content, the weaker the shale is (Mondol et al., 2008). Although the Muderong Shale and Muiron Member (Exmouth Sub-basin) have high contents of smectite (up to 30\%) (Dewhurst and Hennig, 2003), they are still well below the recorded smectite contents from the core samples of the Lakes Entrance Formation. Goldie Divko et al. (2010b) report the smectite contents from the Groper-2, Wrasse-1 and Groper- 1 to be $41 \%, 70 \%$ and $81 \%$ respectively. Such high smectite content will cause the plot of capillary pressure versus $\varepsilon\left[\mathbf{F}\left(\mathbf{P}_{\mathbf{c}}, \boldsymbol{\varepsilon}\right)\right]$ in the Exmouth to be larger than the one in the Gippsland. In mathematical terms: $\mathbf{F}\left(\mathbf{P}_{\mathbf{c}}, \boldsymbol{\varepsilon}\right)_{\text {Gippsland }}<\mathbf{F}\left(\mathbf{P}_{c}, \boldsymbol{\varepsilon}\right)_{\text {Exmouth }}$ where $F$ is a function of capillary pressure and $\varepsilon$ (of seismic anisotropy).

A combination of these four characteristics will be used to predict the variation of sealing capacity of the Lakes Entrance Formation. 


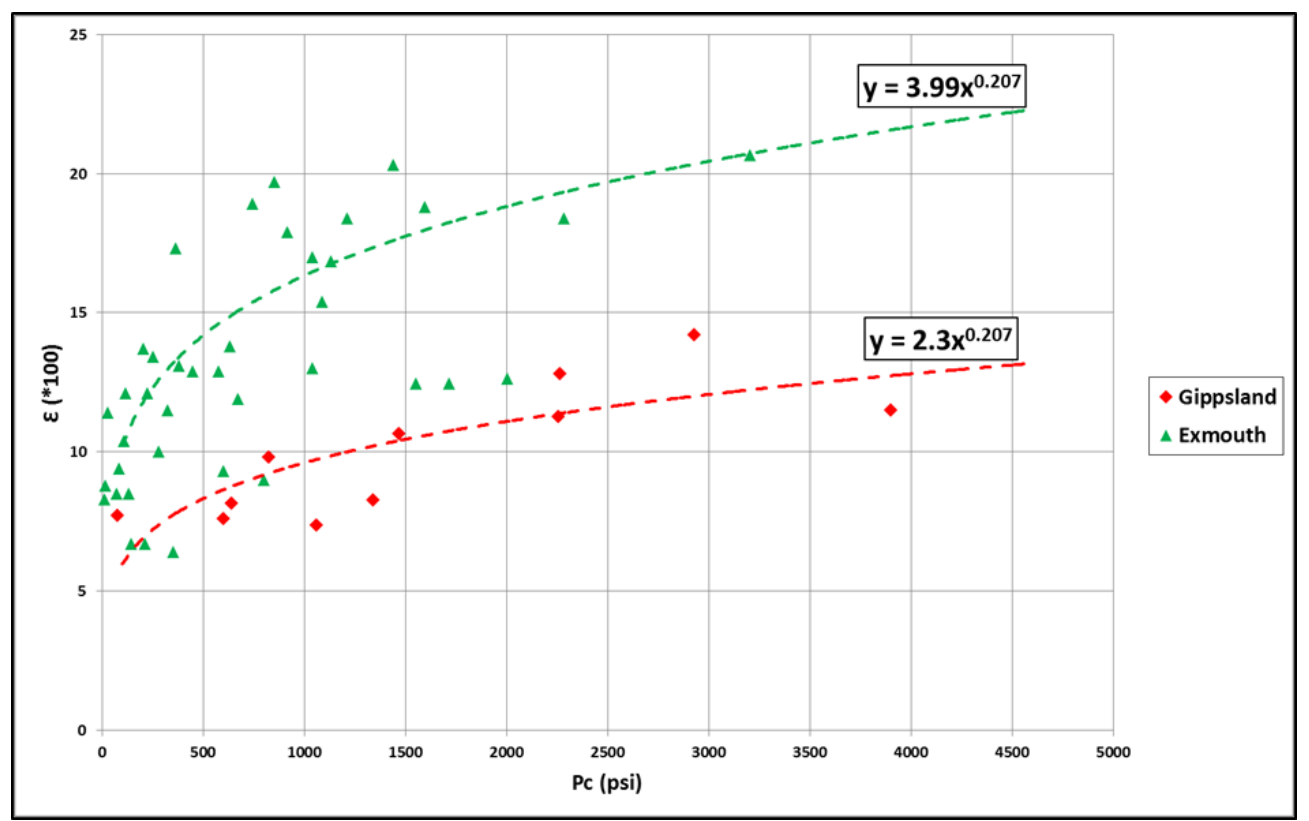

Figure 7. Cross plot of Epsilon versus Capillary Pressure to compare the data from the Exmouth (Nourollah et al., 2015) and the Gippsland Basin (Nourollah, 2018). An overall increase of the sealing capacity can be observed (for each shale) with increasing $\varepsilon$.

\section{The Sealing Potential}

Despite the lack of MICP measurements to calibrate the sealing capacity, powerful tools exist to assess the seal. The chimney sites can also act as calibration points in the sense of where the seal has failed. Hence, testing was carried out over narrow frequency bands for seismic $Q$ as well as testing for the seismic anisotropy parameter $\varepsilon$. The input seismic data were the full-offset stack seismic and the faroffset stack cubes. The near-offset stack was not useful in the analysis due to lack of signal at shallow times. However, the full-offset stack should add enough near- and mid-offset influence to offer a relatively independent signal from the far-offset cube. Spectral decomposition of seismic data offers the narrow frequency bands which are required to implement the applicable extremes of the frequency ranges. Of interest are the extreme practical ends of the frequency spectrum. For the available data, the selected corridors are $20 \mathrm{~Hz}$ and $60 \mathrm{~Hz}$. The data contain useful information beyond the selected 
thresholds, however, very low and very high frequency data from conventional seismic need to be utilized with care.

Figure 8 shows a comparison of the seismic Quality (Q) for the two end members of the offset range within the same frequency bracket. The full-offset stack shows higher $Q$ values over the main chimney site in comparison with those of the surrounding areas (left-hand panel in Figure 8). The higher $Q$ values may be indicative of higher brittleness or better cross-flow which can indicated departure from the "ideal" shale towards a silty shale. This observation is consistent with the seismic evidence of the eruptive nature of the gas chimney and its associated fractures (Figure 4). Both maps highlight areas of potential sealing risk (higher $Q$ values) south of Moby-1 and Flathead-1 (white rectangle in Figure 8). Lower risk of sealing breach is assigned to the areas where both offsets indicate a relatively low seismic quality (warmer colours in Figure 8).

Lab measurements of seismic quality (Ciz et al., 2005; Delle Piane et al., 2014) on shale samples confirm that $Q$ values are higher parallel to the shale bedding than perpendicular to it. Presence of capillary pipes may lower the contrast between the two $Q$ values due to a more effective squirt flow (Dvorkin et al., 1994) across the shale laminae. To test the likelihood of the presence of a capillary network and the size of pores/conduits which act as agents of cross-flow, a comparison between the low and high frequency windows is made (Figure 9 and Figure 8). The main chimney site shows a higher quality seismic response at $60 \mathrm{~Hz}$ in comparison with the $20 \mathrm{~Hz}$. This means seismic is attenuated less in the $60 \mathrm{~Hz}$ window in comparison with the $20 \mathrm{~Hz}$ bracket. One interpretation maybe that there are pores and conduits which help the fluid (gas) flow across the seal, but they are not large enough to have a significant impact on the high frequencies. However, Seismic frequencies are ultra-sonic frequencies for shales (Batzle et al., 2006), but they may help delineate the amount of silt in shale which may open up more crack-like space for capillaries (Sarout and Guéguen, 2008; Sayers, 1999) and identification of 
patchy saturation. This means the low and high frequency bands (20 and $60 \mathrm{~Hz}$ ) likely flag either sides of the peak frequency for the patchy fluid (gas) saturation. This peak frequency was determined to be nearly $42 \mathrm{~Hz}$ for the Goldwyer Shale from Canning Basin, Australia (Delle Piane et al., 2014).

Both frequencies (especially $60 \mathrm{~Hz}$ ) indicate a distinct difference between the chimney area and the surrounding areas. Interestingly, there are some areas (south of the crest of the structure-grey square in Figure 9) which appear to have weak seals on the $20 \mathrm{~Hz}$ map, but they are less distinct on the $60 \mathrm{~Hz}$ map. They may represent weak seals, but not too weak (in relative terms) to be significant on high frequencies. It is also possible that gas patches are not strongly present in those areas to be of significance. Therefore the seal is more competent in terms of its capacity.

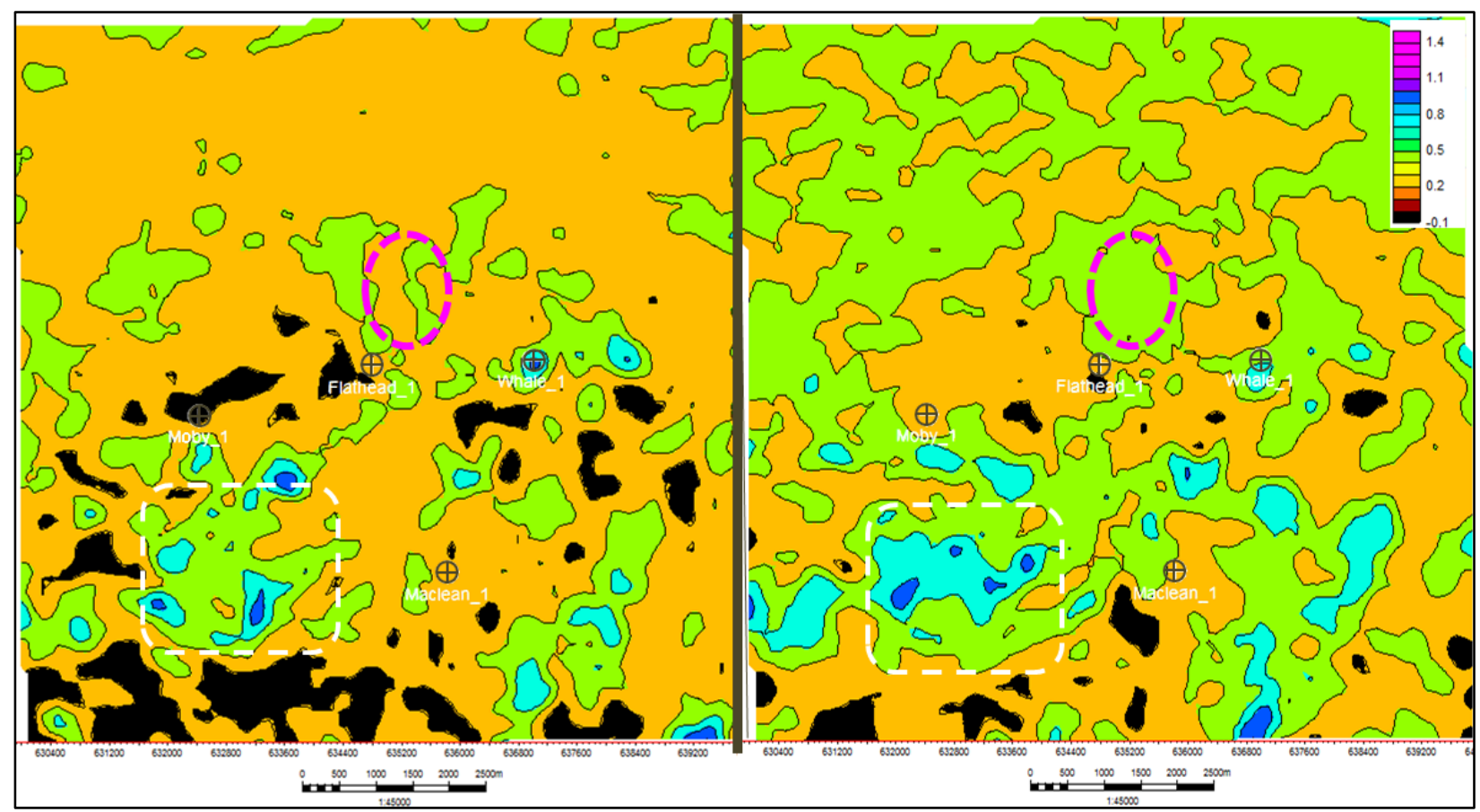

Figure 8. Averaged Seismic Q response of the Lakes Entrance sequence at $20 \mathrm{~Hz}$ window from a stack seismic (Left) and the far stack (right) reveals potential sealing risks especially around the main chimney site north of Flathead-1. The dashed polygon shows the location of the main chimney. 


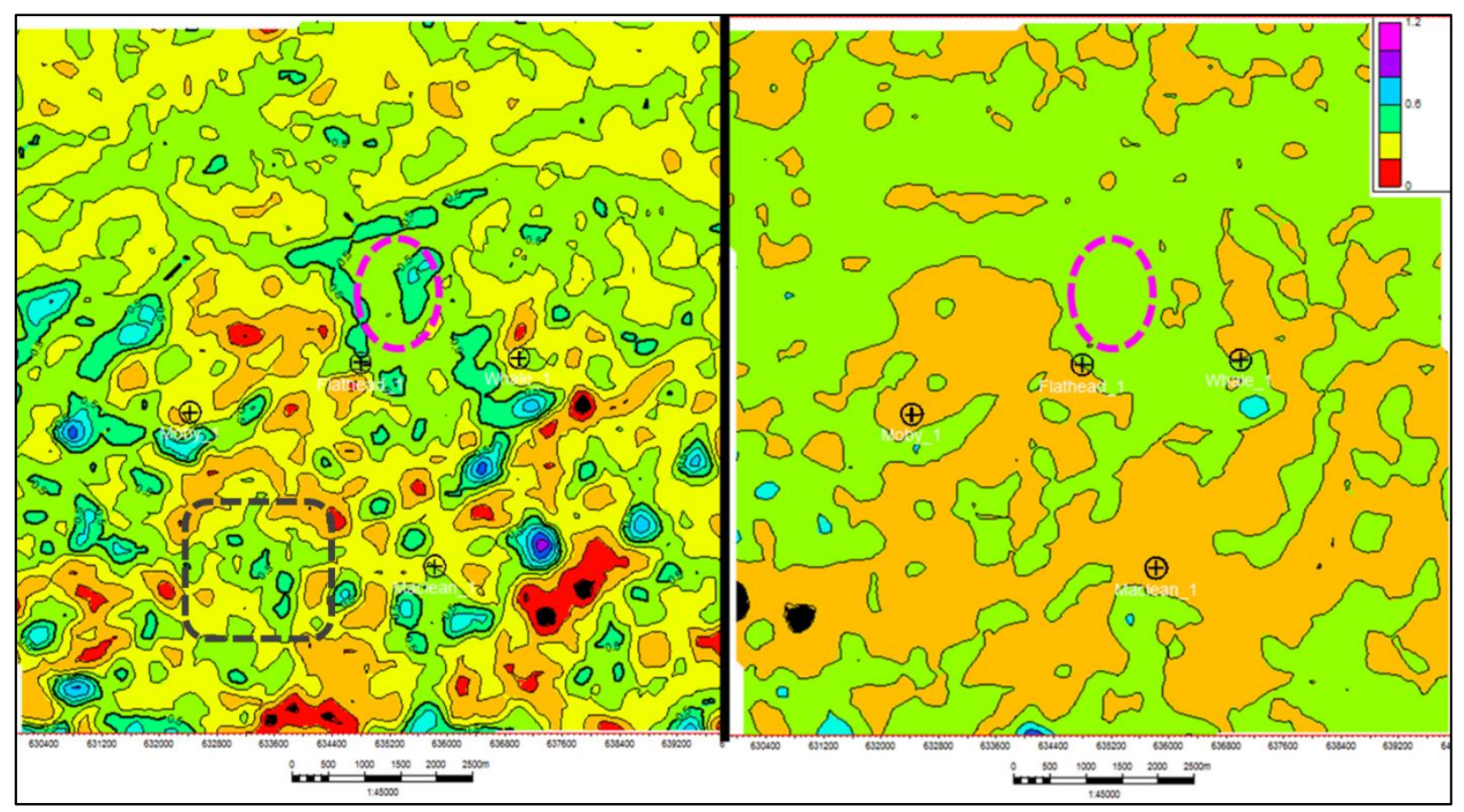

Figure 9. Average seismic Q over the sealing sequence for the $60 \mathrm{~Hz}$ bracket of stack seismic cube (left) and the far-offset (right). The location of the main chimney is shown with a dashed polygon.

The anisotropy parameter $\varepsilon$ can also be considered a proxy for the relative sealing potential.

Nourollah et al. (2015) showed that increasing values of $\varepsilon$ may correlate with higher values of sealing capacity of shales. Figure 10 shows the distribution of average $\varepsilon$ over the Lakes Entrance Formation. The range of $\varepsilon$ varies between 3 and 13, with the majority of the values to be less than 11 . This is notably lower than the range that was observed in the Exmouth sub-basin, but is well within the mid-to-low ranges for the Lakes Entrance Formation. There is an overall match between the variations of $\varepsilon$ and what was observed from the seismic attribute $Q$ (and its narrow-band subsets). It correctly predicts a relatively lower seal capacity at the main chimney location. The map of $\varepsilon$ is relatively smoother and suggests that the lower seal quality areas occur in NE-SW trending stripes. This observation matches the relative structural uplifting in the same direction. Such uplifting caused a more reworked sedimentation, larger input of clastic particles and shallower depth of burial which may all contribute to the 
diminishment of the sealing capacity. It is likely that the episode of marine transgression and deposition/erosion of the sealing sequence was happening in the NW-SE direction (in the area of study).

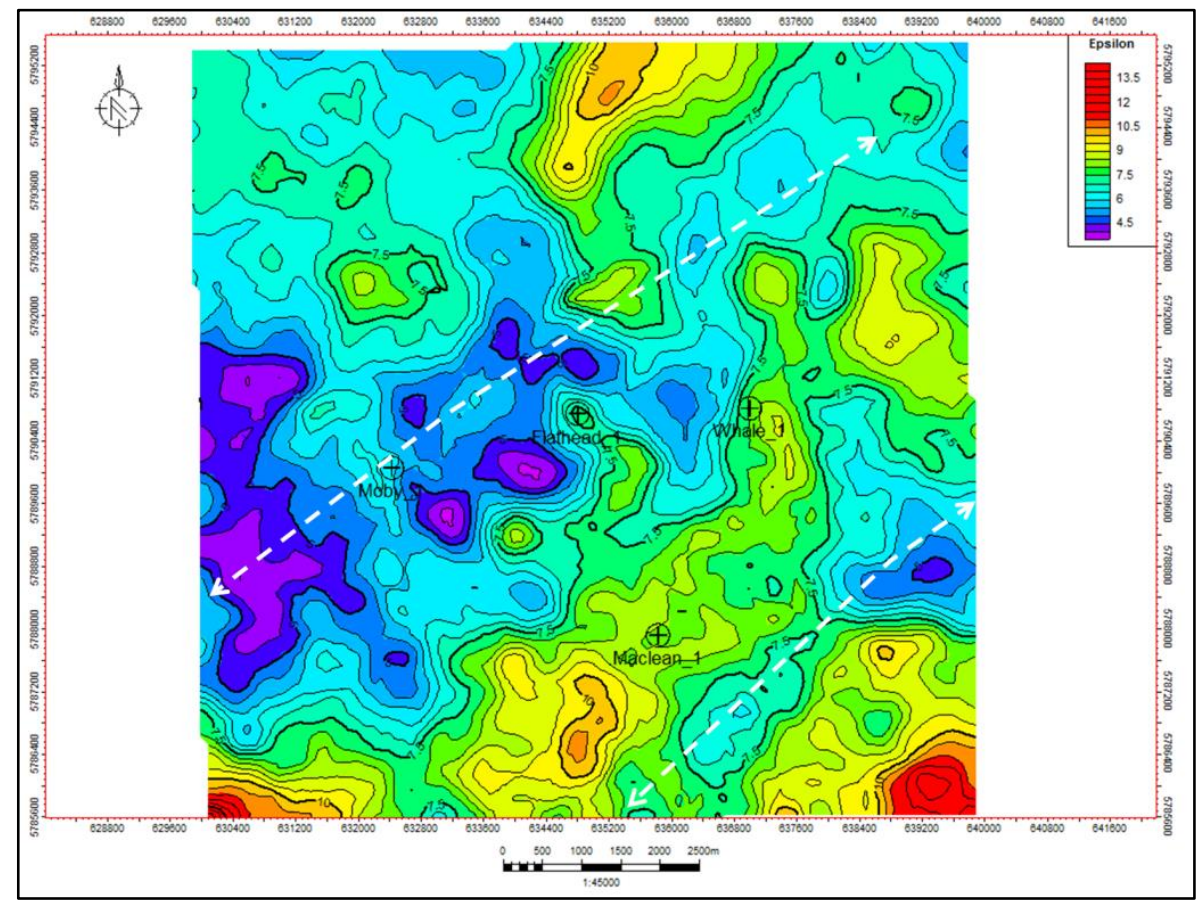

Figure 10. Map of anisotropy parameter epsilon averaged over the sealing sequence. The white stripes show two parallel trends in the lower $\varepsilon$ (corresponding to lower sealing capacity) areas.

Using the inverse function of $F_{G i p p s l a n d}\left(P_{c}, \varepsilon\right)$ from Figure 7 , the sealing potential of the Lakes Entrance in the area of study can be estimated. Figure 11 shows the estimated sealing potential (displayed as Capillary threshold pressure values) overlain on the Lakes Entrance depth structure contours. The NE-SW stripes of low sealing capacity (low capillary threshold pressure) can be observed, indicating high risk areas, particularly southwest of Flathead-1 and Moby-1. It is interesting to observe that the lowest sealing capacity areas do not correspond to the location of the main gas chimney. The reason is that a seal leaks when the buoyancy pressure of the underlying fluid column is higher than its sealing capacity. The highest buoyancy pressure normally occurs at the crest of the structures where buoyant fluids (oil-gas) migrate to. Therefore, in relative terms, the seal must be at its best capacity in 
the critical areas such as the crest of the structure, but can be weaker on the flanks. This did not happen on the Flathead high, resulting in the formation of the main chimney.

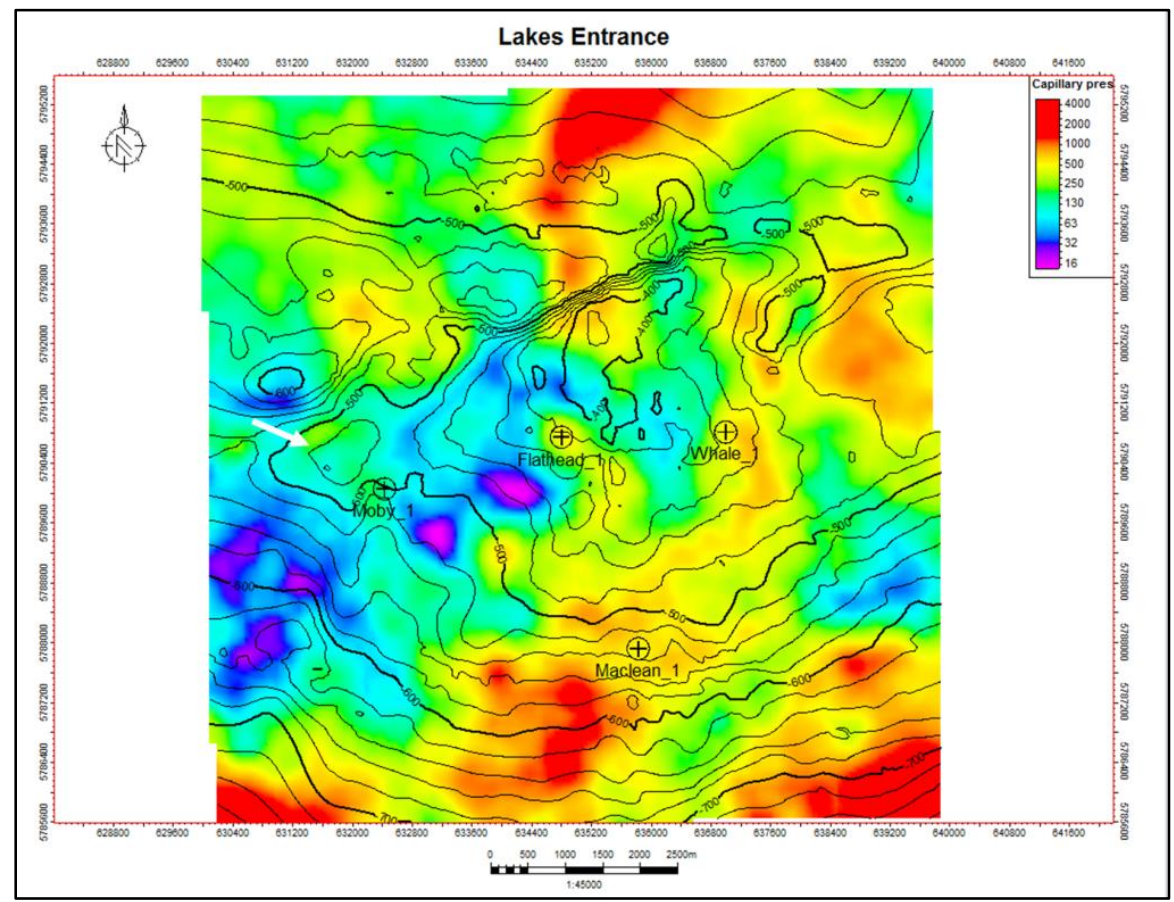

Figure 11. Average sealing potential of the Lakes Entrance Formation shows relative low capacity sealing bands over the crest of the structure stretched towards SW. Contours are the top Lakes Entrance depth.

An immediate result from the map of Figure 11 is to estimate the highest hydrocarbon column height that could have existed in the AOI given the sealing capacity. The chimney is just an indication of failure in the face of pressure that exceeds the sealing capacity. There could be a remnant HC column underneath the breached seal. The highest sealing capacity at the crest of the structure is around $110^{\mathrm{psi}}$ (Figure 11). This is a very weak seal corresponding to the D-class on Sneider's scale (Sneider et al., 1997).

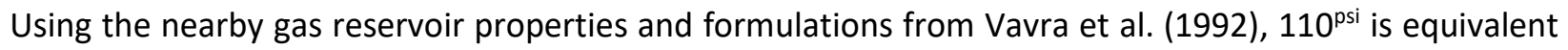
to $\sim 15^{\mathrm{m}}$ gas column. The low threshold for the sealing pressure suggests the unlikely potential for commercial accumulation of hydrocarbon. There are however some areas where a relatively competent seal is capping a local structural high. An example is the closure NW of Moby-1 (white arrow in Figure 
11) where the average sealing capacity is in excess of $300^{\mathrm{psi}}$ with some layers of the seal reaching as high as $500^{\text {psi }}$. A local flat spot can be recognized on the seismic data in this locality (Figure 12).

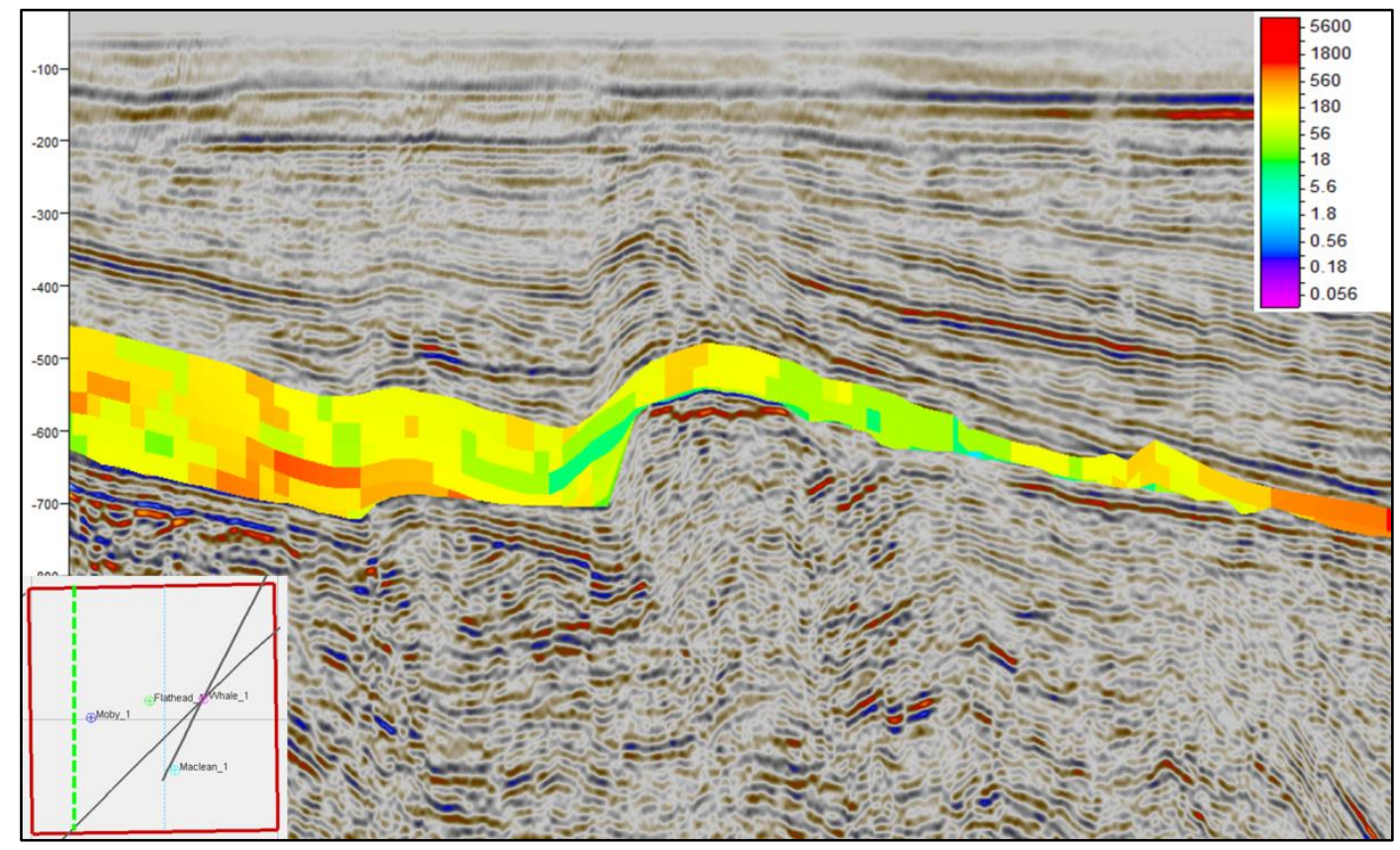

Figure 12. Inline 2119 (green dashed line in map insert) of the 3D cube crosses over a local structure NW of Moby-1. The overlain predicted sealing capacity (coloured interval) shows a relatively better at the crest (orange) seal compared to the surrounding areas (green). A flat spot in the structure can be observed.

The observation that the seabed does not have any significant pockmarks (Cathles et al., 2010) matches the findings that the top seal was never strong enough to hold a large column of gas. Therefore the gas reached a critical height (for the weak seal) and escaped (better to say oozed) through the seal. The chimney column made some geomechanical changes to the upper half of the sediment cover rocks ,between the forefront of the uprising gas chimney and the seabed, and caused some fractures and escaped (Figure 4). However, this was not in an eruptive way as the seal was never strong enough to hold pressure high enough to cause substantial eruption. Leakage has continued ever since and is still detectable nowadays (Goldie Divko et al., 2010b). 


\section{Conclusion}

The site of a gas chimney in the northern terrace of the Gippsland Basin was evaluated for its sealing potential. The chimney area has been mentioned in several previous studies before and seismic attributes had been used to define its geometry and location. In this paper, seismic attributes and anisotropy were used to evaluate the variations of the sealing potential of the Lakes Entrance formation. Both methods showed consistent results in the variation of sealing capacity in the area of study. The chimney site was used as a calibration point where the seal has failed to maintain a gas column. The results were shown to be consistent with the findings of the exploration wells and previous studies. The mere presence of a chimney does not necessarily indicate lack of commercial accumulation of hydrocarbon since the seal might have leaked under a very high buoyancy pressure. Therefore, there may still be a viable hydrocarbon column underneath the cap rock. However, for the area of study of this paper, it is demonstrated that the sealing potential of the Lakes Entrance is not high enough to hold any commercial column of hydrocarbon on the Flathead high. There appear to be locally competent seals entrapping hydrocarbons in local highs, with evidence in once case of a flat spot.

Where there is no calibration point available (for capillary pressure measurements), the $\varepsilon$ values can be used to qualitatively differentiate between the better seals and weaker seals. Analogues help to quantify expected $\varepsilon$ ranges. These techniques can provide valuable de-risking tools in frontier exploration areas, $\mathrm{CO} 2$ sequestration and evaluation of stratigraphic traps. The growing need for the CCS (Carbon Capture and Storage) requires better knowledge of the variation in capacity. This study introduces better means to lower the associated costs and risks in seal evaluation. 


\section{References}

Aminzadeh, F., Connolly, D., and Groot, P. d., Interpretation of gas chimney volumes, in Proceedings 72nd Annual International Meeting2002, Volume Expanded Abstracts, p. 440-443.

Bandyopadhyay, K., Dvorkin, J., and Mavko, G., 2009, Attenuation and attenuation-anisotropy in laminated rocks: SEG Houston 2009 International Exposition and Annual Meeting.

Batzle, M., Han, D., and Hofmann, R., 2006, Fluid mobility and frequency-dependent seismic velocity Direct measurements: GEOPHYSICS, v. 71, no. 1, p. N1-N9.

Cartwright, J., Huuse, M., and Aplin, A., 2007, Seal bypass systems: AAPG Bulletin, v. 91, no. 8, p. 11411166.

Cathles, L. M., Su, Z., and Chen, D., 2010, The physics of gas chimney and pockmark formation, with implications for assessment of seafloor hazards and gas sequestration: Marine and Petroleum Geology, v. 27, no. 1, p. 82-91.

Ciftci, B., Langhi, L., Strand, J., and Goldie Divko, L., 2014, Efficiency of a faulted regional top seal, Lakes Entrance Formation, Gippsland Basin, SE Australia: Petroleum Geoscience, v. 20, no. 3, p. 241256.

Ciz, R. M., Urosevic, M., and Dodds, K. J., 2005, Pore pressure prediction based on seismic attributes response to overpressure: APPEA Journal, v. 1, p. 1-10.

Dawson, W. C., Almon, W. R., Dempster, K., and Sutton, S. J., 2008, Shale Variability in Deep-Marine Depositional Systems: Implications for Seal Character - Subsurface and Outcrop Examples: Search and Discovery.

Dawson, W. C., Almon, W. R., and Johansen, S. J., 2004, Seal and Reservoir Characterization of Upper Slope Fan Lithofacies: Example of High-Frequency Variability: Search and Discovery.

Delle Piane, C., Sarout, J., Madonna, C., Saenger, E. H., Dewhurst, D. N., and Raven, M., 2014, Frequencydependent seismic attenuation in shales: experimental results and theoretical analysis: Geophysical Journal International, v. 198, no. 1, p. 504-515.

Dewhurst, D. N., and Hennig, A. L., 2003, Geomechanical properties related to top seal leakage in the Carnarvon Basin-NW shelf Australia: Petroleum Geoscience, v. 9, p. 255-263.

Duddy, I. R., and Green, P. F., 1992, Tectonic development of Gippsland Basin and environs: identification of key episodes using Apatite Fission Track Analysis (AFTA), in Hill, K. C., Abele, C., Foster, J., and Kempton, N., eds., Energy, Economics and Environment - Gippsland Basin Symposium, Australasian Institute of Mining and Metallurgy, p. 111-120.

Dvorkin, J., and Mavko, G., 2006, Modeling attenuation in reservoir and nonreservoir rock: The Leading Edge, v. 25, no. 2, p. 194-197.

Dvorkin, J., Nolen-Hoeksema, R., and Nur, A., 1994, The squirt-flow mechanism: Macroscopic description: GEOPHYSICS, v. 59, no. 3, p. 428-438.

Goldie Divko, L., Hamilton, J., and O'Brien, G. W., 2010a, Evaluation of the Regional Top Seal for the Purpose of Geologic Sequestration in the Gippsland Basin, Southeastern Australia, AAPG Convention: New Orleans, Louisiana.

Goldie Divko, L., O'Brien, G. W., Harrison, M. L., and Hamilton, P. J., 2010b, Evaluation of the regional top seal in the Gippsland Basin: Implications for geological carbon storage and hydrocarbon prospectivity, $463-486$ p.:

Kaldi, J. G., and Atkinson, C. D., 1997, Evaluating seal potential: example from the Talang Akar Formation, offshore northwest 
Java, Indonesia, Seals, traps, and the petroleum system, Volume 67, p. 85-101.

Mondol, N. H., Jahren, J., Bjørlykke, K., and Brevik, I., 2008, Elastic properties of clay minerals: The Leading Edge, v. 27, no. 6, p. 758-770.

Norvick, M. S., Smith, M. A., and Power, M. R., 2001, The plate tectonic evolution of eastern Australasia guided by the stratigraphy of the Gippsland Basin, in Hill, K. C., and Bernecker, T., eds., Eastern Australasian Basins Symposium, A Refocused Energy Perspective for the Future, Petroleum Exploration Society of Australia, p. 15-23.

Nourollah, H., 2018, Sealing Potential of Shale Sequences through Seismic Anisotropy Analysis [PhD: Curtin University of Technology.

Nourollah, H., Keetley, J., and O'Brien, G., 2010, Gas chimney identification through seismic attribute analysis in the Gippsland Basin, Australia: The Leading Edge, v. 29, no. 8, p. 896-901.

Nourollah, H., Urosevic, M., and Keetley, J., 2015, Seal potential of shale sequences through seismic anisotropy: Case study from Exmouth Sub-basin, Australia: Interpretation, v. 3, no. 4, p. T257T267.

Partridge, A. D., Kelman, A. P., Khider, K., Le Poidevin, S., and Mantle, D. J., 2012, Gippsland Basin, Biozonation and Stratigraphy, in 40, C., ed., Geoscience Australia.

Rahmanian, V. D., Moore, P. S., Mudge, W. J., and Spring, D. E., 1990, Sequence stratigraphy and the habitat of hydrocarbons, Gippsland Basin, in Brooks, J., ed., Classic Petroleum Provinces, Volume Special Publications, Geological Society, London, p. 525-541.

Sarout, J., and Guéguen, Y., 2008, Anisotropy of elastic wave velocities in deformed shales: Part 2 Modeling results: GEOPHYSICS, v. 73, no. 5, p. D91-D103.

Sayers, C. M., 1999, Stress-dependent seismic anisotropy of shales: Geophysics, v. 64, p. 93-98.

Sheriff, R. E., and Geldart, L. P., 1995, Exploration seismology, Cambridge University Press.

Sneider, R. M., Sneider, J. S., Bolger, G. W., and Neasham, J. W., 1997, Comparison of Seal Capacity Determinations: Conventional Cores vs. Cuttings, in Surdam, R. C., ed., AAPG Memoir 67, Volume 67, The American Association of Petroleum Geologists, p. 1-12.

Taner, M. T., 2001, Seismic attributes: CSEG Recorder, v. 26, no. 9, p. 48-56.

Thomsen, L., 1986, Weak elastic anisotropy: GEOPHYSICS, v. 51, no. 10, p. 1954-1966.

Vavra, C. L., Kaldi, J. G., and Sneider, R. M., 1992, Geological Applications of Capillary Pressure A review: AAPG Bulletin, v. 76, no. 6, p. 840-850. 